\title{
Synthesis and Characterization of Polyvinyl Chloride Chemically Modified by Amines
}

\author{
Ameer A. Ameer ${ }^{1}$, Mustafa S. Abdallh ${ }^{2}$, Ahmed A. Ahmed ${ }^{3}$, Emad A. Yousif ${ }^{2}$ \\ ${ }^{1}$ College of Engineering and Computing, Al-Ghurair University, Dubai, UAE \\ ${ }^{2}$ Department of Chemistry, College of Science, Al-Nahrain University, Baghdad, Iraq \\ ${ }^{3}$ Polymer Research Unit, College of Science, Al-Mustansiryah University, Baghdad, Iraq \\ Email: bayati@agu.ac.ae
}

Received December 13, 2012; revised January 11, 2013; accepted January 23, 2013

\begin{abstract}
The reactions of poly vinyl chloride (PVC) with different aliphatic amines in Tetra Hydro Furan, THF, have been studied. These reactions led to the formation of new polymers (PVC-L) which were characterized by spectroscopic methods (Infra Red, IR and Uv-Visible spectrophotometry). Composite of the new polymers were prepared and their optical activities in the region $(200-400 \mathrm{~nm})$ were studied. The optical data analyzed and interpreted using the theory of phonon assisted direct electronic transition.
\end{abstract}

Keywords: PVC; Optical Properties; Energy Gap

\section{Introduction}

Polymer composites have a long history. Despite these materials are still one of the most dynamically development materials in the $21^{\text {st }}$ century because of the ability propose to not only reduce cost, but to improve properties, such as mechanical, thermal and barrier properties of the final polymer product. Polyvinyl chloride (PVC) is one of the most extensive thermoplastic materials in the world due to its valuable properties, wide applications, high chemical resistance, barrier properties and low cost $[1,2]$. On the other hand, thermal stability and processibility of PVC is inferior compared with common polymers, for example polyethylene (PE), polypropylene (PP), polyamide (PA). These properties could be reinforced compounding PVC with inorganic or organic fillers. The most useful fillers in PVC are calcium carbonate, kaolinite, and calcined kaolinite $[3,4]$. Synthesis of polymerbound chelating ligands and the selective chelation of specific metal ions is a field of active research [5]. A number of ligands including polydentate amines, crown ethers, phosphines and bipyridines have been bound with mainly polystyrene divinylbenzene copolymers $[6,7]$. These studies are mostly concerned with ion-binding and catalytic aspects. Very little information appears to exist as to whether, and to what extent, such organic compounds can influence the properties of the macromolecule. Recently, scientists were able to modify PVC by introduction aromatic and heterocyclic moieties through halogen displacement reaction. PVC, thus modified, showed improved overall photochemical stability [8].
The facial chlorine displacement from PVC indicated the possibility on easy anchoring of ligands to PVC matrix and the subsequent synthesis of immobilized transition metal complexes [9]. This article will describe the synthesis and biological evaluation of 1,3,4-thiadiazole and phthalyl groups as a pending groups into the repeating unit of PVC polymer. In recent years, studies on the electrical and optical properties of polymers have attracted much attention in view of their applications in optical devices with remarkable reflection, antireflection, interference and polarization properties [10-12].

The optical properties of amorphous semiconductors have been the subject of many recent papers. The study of the optical constants of materials is interesting for many reasons. First, the use of materials in optical fibers and reflected coating requires accurate knowledge of their optical constants over wide ranges of wavelength. Second, The optical properties of all materials are related to their atomic structure, electronic band structure and electrical properties [13,14].

The optical properties of polymers can be suitably modified by the addition of dopants depending on their reactivity with the host matrix. The amines polymer are fast-conducting complexes in a number of crystalline and amorphous materials, its incorporation in a polymeric system may be expected to enhance its electrical and optical performance.

PVC intrinsic properties make it suitable for a wide variety of applications. It is biologically and chemically resistant, making it the plastic of choice for most house- 
hold sewerage pipes and other pipe applications where corrosion would limit the use metal [15]. The aim of this work is to focus on the optical parameters of PVC. In this paper, we present results of such a study on the optical properties of pure and other polymers PVC films.

\section{Experimental}

\subsection{Purification of Poly(vinyl Chloride)}

Commercial Poly(vinyl chloride) (Petkim company, Turkey) was purified by re-precipitation from tetrahydrofuran (THF) solution in ethanol, then dried under reduced pressure at room temperature for 24 hours.

\subsection{Polymer Modification}

The modification of PVC with different amines was performed by dissolving $0.1 \mathrm{~g}$ of PVC in THF then add 0.05 mole of amine. 5 drops of pyridine was added to the mixture. The reaction mixture was refluxed for $4-6$ hours. The precipitated modified polymers were separated as film by evaporating the solvent (THF). In case of polymer modification with dicyclohexylamine and dipropyle amine, it took more time of reflux than other amines. This time difference may be due to steric effect in these two molecules which may have also caused a lower percentage yield.

The color prepared polymer and time of reflux are listed in Table 1.

\subsection{Films Preparation}

$0.5 \%$ concentrations of PVC solution in THF was used to prepare 30 - 40 micrometer thickness of polymer films, (measured by a micrometer type 2610 A, Germany). The films were prepared by evaporation technique at room temperature for $24 \mathrm{~h}$. film samples were further dried at room temperature for five hours under reduced pressure to remove the possible residual THF solvent. The optical absorbance (A) of the sample was measured as a function of wavelength $(\lambda)$ ranged from $200-400 \mathrm{~nm}$ by using computerized Shimadzu Uv-Vis 160A-Ultraviolet-spectrophotometer full-scale absorbance up to (2.5). The light sources are halogen lamp and socket-deuterium lamp. The detector is Si-photodiode and all measurements were

Table 1. List of the prepared polymers, time of reflux, yield and color.

\begin{tabular}{cccc}
\hline Amine & Reflux Time & Yield & Polymer Color \\
\hline Dicyclohexylamine & 6 & $51 \%$ & Pal yellow \\
Iso-butyl amine & 4 & $69 \%$ & Brown \\
Dipropyl amine & 5 & $56 \%$ & Brown \\
Ethylene diamine & 4 & $73 \%$ & Yellow \\
Tert-butyl amine & 4 & $68 \%$ & Pal yellow \\
\hline
\end{tabular}

performed at room temperature. UV/VIS absorption spectroscopies were made for prepared samples before and after modification. The spectra were used to carry out the energy gap by plotting $(\alpha h v)^{r}$ versus $(h v)$ with $(r)$ value (2) which indicates a transition of direct type. The linear portion was best fitted with $(r=2)$ Energy gap shift for all samples plotted as a function to conjunction type [16].

\section{Results and Discussion}

The modification of PVC with amines is initiated by the nucleophilic attack of $(\mathrm{N})$ atom on the carbon carrying chlorine atom in the polymeric chain followed by displacement of chloride anion as a good leaving group.

The structure of modified polymers can be demonstrated by using FTIR and UV/VIS. Spectroscopy. Each polymer showed its own absorption bands. The modification of PVC with amine can be demonstrated by FTIR spectroscopy; the disappearance of the absorption band due to $\left(-\mathrm{NH}_{2}\right)$ stretching frequencies of amine clearly indicates the reaction between PVC and the amine. This compound clearly shows characteristic vibrations of the $\mathrm{C}-\mathrm{N}$ and N-H. Moreover, in PVC-amine (modified polymer) spectrum one can see the following feature: a strong band at $v(631) \mathrm{cm}^{-1}$. This band could be attributed to $v$ (C-Cl) band which is different from the unmodified PVC $v(616) \mathrm{cm}^{-1}$.

When going to the UV/VIS. electronic spectra of the modified polymers, absorption bands that could be attributed to the $\mathrm{n} \rightarrow \pi^{*}$ electronic transitions are noticed. These transitions are assigned in relevance to the structures of compounds and polymers. As shown in Table 2. The increase of the absorbance in the UV/VIS. range for samples containing modified PVC compared with (PVC) can be explained by the presence of a lone pair of electrons on the $\mathrm{N}$-atom (band corresponding to the $\mathrm{n} \rightarrow \pi^{*}$ transition). Thus, shifting the absorbance to longer wavelengths (i.e. the bathochromic effect) is good evidence that modification took place in our PVC and compounds. On the basis of the preceding discussion, the structures of the modified polymers were suggested as shown in Table 2.

Figures 1-6 show the relationship between $(\alpha h v)^{2}$ against the energy for the pure and modified polymer for allowed transition, there is a shift in the energy gap for the modified polymers due to formation of polarons which made the reaction in band to band transition due to shifting the band density of state toward the energy gap. this behavior differ from doping of semiconductor when the band to band absorption strength does not affected by the formation of dopant state in the energy gap. the results revealed two polarons band, the first one represent the transition from valance band anti-bonding polarons and the other one represent the transition from valance 
Table 2. The suggested structures of the modified polymers.

\begin{tabular}{|c|c|c|c|c|}
\hline Compound & $\operatorname{IR}\left(\mathrm{cm}^{-1}\right)$ & Assignments & $\begin{array}{l}\text { Absorption } \\
\text { Bands nm }\end{array}$ & Suggested Structure \\
\hline PVC & $\begin{array}{c}2911 \\
616\end{array}$ & $\begin{array}{l}\mathrm{C}-\mathrm{H} \\
\mathrm{C}-\mathrm{Cl}\end{array}$ & 270 & $\mathrm{Cl}$ \\
\hline P1 & $\begin{array}{c}1254 \\
2926 \\
615\end{array}$ & $\begin{array}{c}\text { C-N } \\
\text { C-H aliphatic } \\
\text { C-Cl }\end{array}$ & 240 & \\
\hline $\mathrm{P} 2$ & $\begin{array}{c}3307 \\
2965 \\
636 \\
1215\end{array}$ & $\begin{array}{c}\mathrm{N}-\mathrm{H} \\
\mathrm{C}-\mathrm{H} \text { (aliphatic) } \\
\mathrm{C}-\mathrm{Cl} \\
\mathrm{C}-\mathrm{N}\end{array}$ & 230,262 & \\
\hline P3 & $\begin{array}{c}1253 \\
2911 \\
630\end{array}$ & $\begin{array}{c}\mathrm{C}-\mathrm{N} \\
\mathrm{C}-\mathrm{H} \text { (aliphatic) } \\
\mathrm{C}-\mathrm{Cl}\end{array}$ & 280 & I \\
\hline P4 & $\begin{array}{c}3304 \\
2970 \\
632 \\
1195\end{array}$ & $\begin{array}{c}\mathrm{N}-\mathrm{H} \\
\mathrm{C}-\mathrm{H} \text { (aliphatic) } \\
\mathrm{C}-\mathrm{Cl} \\
\mathrm{C}-\mathrm{N}\end{array}$ & 228,278 & \\
\hline P5 & $\begin{array}{c}3312 \\
2930 \\
617 \\
1087\end{array}$ & $\begin{array}{c}\mathrm{N}-\mathrm{H} \\
\mathrm{C}-\mathrm{H} \text { (aliphatic) } \\
\mathrm{C}-\mathrm{Cl} \\
\mathrm{C}-\mathrm{N}\end{array}$ & 241,269 & E \\
\hline
\end{tabular}

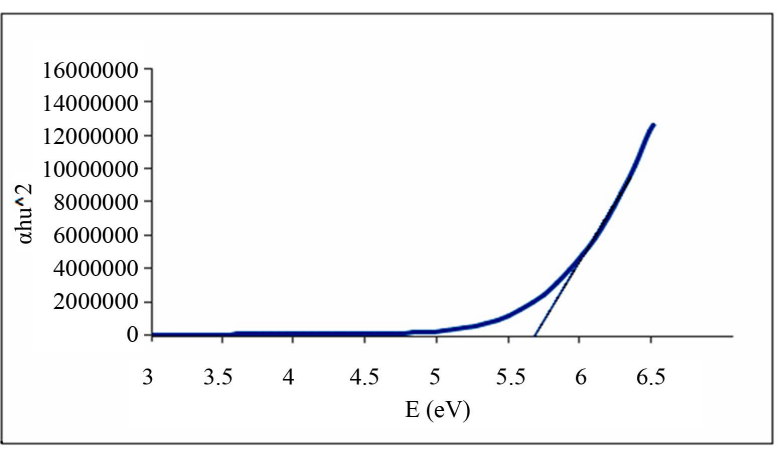

Figure 1. Allowed direct transition $(\alpha h v)^{2}$ vs energy for pure PVC.

band to bonding polaron band, these results agreed with the results obtained by Yousif et al., Abdul Nabi et al. and Al-Ramadin [17,18,11]. The effect of PVC modification with aromatic amines was studied by Al-Daeif et al. [19]. In this study the same effect with aliphatic amines was studied. The values of phonon energies are shown in Table 3. The Energy gaps were measured as behavior of a conductivity measurement of PVC with and without additive and can be obtained by adopting the data of energy gap, (see Table 3 and Figures 1-6. The conductivity measurement for PVC in the presence of additive increases in the following order:

$$
\mathrm{PVC}>\mathrm{P} 3>\mathrm{P} 4>\mathrm{P} 5>\mathrm{P} 2>\mathrm{P} 1 \text {. }
$$

\section{Conclusion}

The optical properties of the PVC polymers modified with aliphatic amines have been measured in the Uv-Vis. 


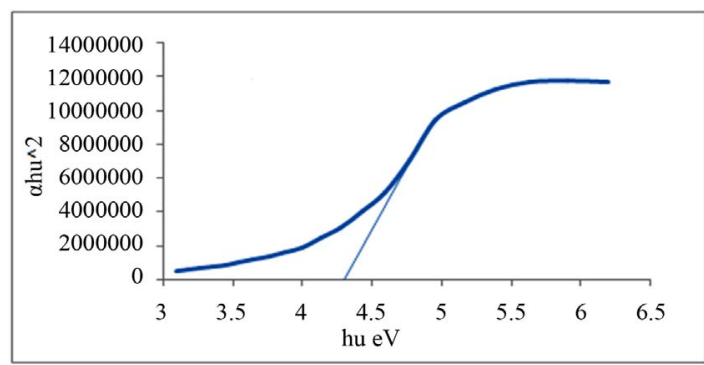

Figure 2. Allowed direct transition $(\alpha h v)^{2}$ vs energy for P1.

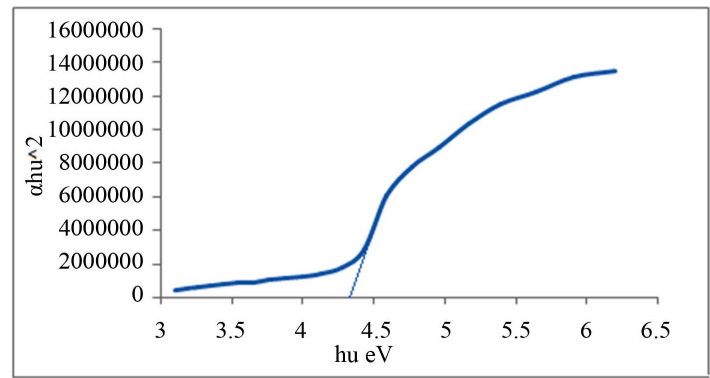

Figure 3. Allowed direct transition $(\alpha h v)^{2}$ vs Energy for P2.

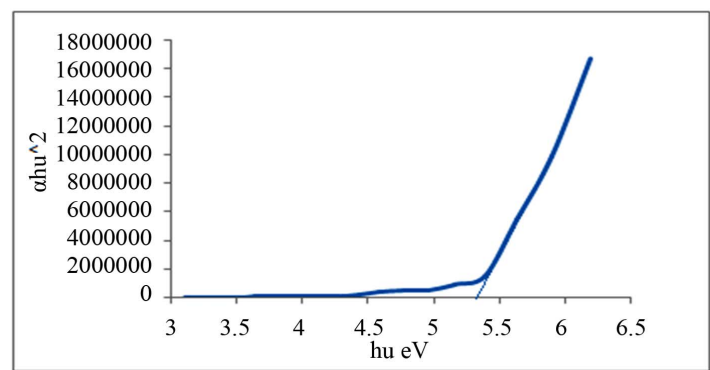

Figure 4. Allowed direct transition $(\alpha h v)^{2}$ vs Energy for P3.

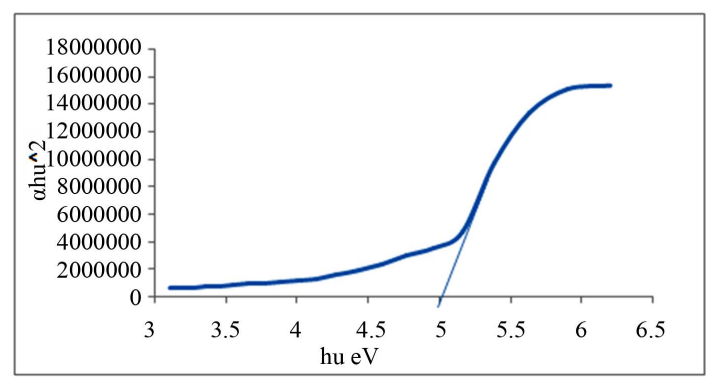

Figure 5. Allowed direct transition $(\alpha h v)^{2}$ vs Energy for P4.

Table 3. Indicates the energy band gap according to the direct allowed transition.

\begin{tabular}{cc}
\hline Polymer & $\mathrm{Eg}(\mathrm{eV})$ \\
\hline PVC & 5.7 \\
P1 & 4.33 \\
P2 & 4.35 \\
P3 & 5.38 \\
P4 & 5.1 \\
P5 & 4.7 \\
\hline
\end{tabular}

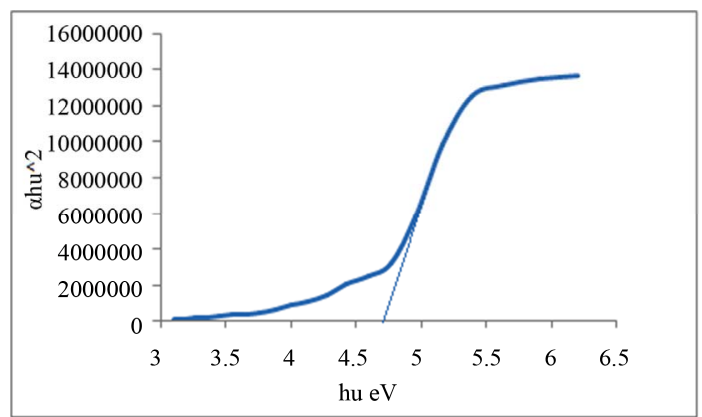

Figure 6. Allowed direct transition $(\alpha h v)^{2}$ vs Energy for P5.

region. These properties were determined using the Energy Gap method as a calculation method and found to vary according to the modification.

\section{Acknowledgements}

This work has been supported by the Department of Chemistry, College of Science, Al-Nahrain University and to Polymer Research Unit, College of Science, Al-Mustansiryah University and in-part by the College of Engineering and Computing, Al-Ghurair University, Dubai, UAE.

\section{REFERENCES}

[1] S. Zhu, Y. Zhang, Y. Zhang and C. Zhang, "Effect of $\mathrm{CaCO}_{3} / \mathrm{LiCO}_{3}$ on the $\mathrm{HCl}$ Generation of PVC during Combustion," Polymer Testing, Vol. 2, No. 5, 2003, pp. 539-543. doi:10.1016/S0142-9418(02)00150-2

[2] F. Gong, M. Feng, C. Zhao, S. Zhang and M. Yang, "Thermal Properties of Poly(vinyl Chloride)/Montmorillonite Nanocomposites," Polymer Degradation and Stability, Vol. 84, No. 2, 2004, pp. 289-294. doi:10.1016/i.polymdegradstab.2003.11.003

[3] M. Pan, X. Shi, X. Li, H. Hu and L. Zhang, "Morphology and Properties of PVC/Clay Nanocomposites via in Situ Emulsion Polymerization," Journal of Applied Polymer Science, Vol. 94, No. 1, 2004, pp. 277-286. doi:10.1002/app.20896

[4] A. B. Shehata, M. A. Hassan and N. A. Darwish, "Kaolin Modified with Resin-Iron Chelate as Flame Retardant System for Polypropylene," Journal of Applied Polymer Science, Vol. 92, No. 5, 2004, pp. 3119-3125. doi:10.1002/app.20226

[5] Y. Chen, Y. Song, Y. Zhang and J.-P. Lang, "A Tricobalt(II) Coordination Polymer Incorporating in Situgenerated 5-Methyltetrazolate Ligands," Inorganic Chemistry Communications, Vol. 11, No. 5, 2008, pp. 572-575. doi:10.1016/j.inoche.2008.02.015

[6] B. Gustafsson, B. Hakansson and S. Jagner, "Complexes between Copper(I) Chloride and Polydentate Aromatic Amines," Inorganica Chimica Acta, Vol. 350, No. 4, 2003, pp. 209-214. doi:10.1016/S0020-1693(02)01548-7

[7] Z. Genhua and C. Pan, "Preparation of Star Polymers Based on Polystyrene or Poly(styrene-b-N-isopropyl 
acrylamide) and Divinylbenzene via Reversible AdditionFragmentation Chain Transfer Polymerization," Polymer, Vol. 46, No. 8, 2005, pp. 2802-2810. doi:10.1016/j.polymer.2005.01.071

[8] E. Yousif, A. Hameed and E. Bakir, "Synthesis and Photochemical Study of Poly(vinyl chloride)-1,3,4-oxadiazole and 1,3,4-Thiadiazole," Journal of Al-Nahrain University (Science), Vol. 10, No. 1, 2007, pp. 7-12.

[9] S. Aliwi, E. Yousif and A. Otaiwi, "Synthesis and Photochemical Study of Some Metal Complexes of Poly(vinyl chloride)-2-mercapto-5-phenyl 1,3,4-oxadiazole," Iraqi Journal of Polymers, Vol. 10, No. 1, 2005, pp. 53-64.

[10] C. V. S. Reddy, Q.-Y. Zhu, L.-Q. Mai and W. Chen, "Optical, Electrical and Discharge Profiles for $\left(\mathrm{PVC}+\mathrm{NaIO}_{4}\right)$ Polymer Electrolytes," Journal of Applied Electrochemistry, Vol. 36, No. 9, 2006, pp. 1051-1056. doi:10.1007/s10800-006-9158-3

[11] Y. Al-Ramadin, "Optical Properties of Poly(vinyl Chloride)/Poly(ethylene Oxide) Blend," Optical Materials, Vol. 14, No. 4, 2000, pp. 287-290. doi:10.1016/S0925-3467(00)00007-0

[12] J. Tauc, “Amorphous and Liquid Semiconductor," Plenum Press, London, New York, 1974. doi:10.1007/978-1-4615-8705-7

[13] M. Youssif, A. Bahgat and A. Ali, "Ac Magnetic Susceptibility Technique for the Characterization of High Temperature Superconductors," Egyptian Journal of Solids,
Vol. 23, No. 2, 2000, pp. 231-250.

[14] N. Mott and E. Davis, "Electronic Process in Non-Crystalline Materials," 2nd Clarendon Press, Oxford, 1979, pp. 458-465.

[15] B. John, "Polyvinyl Chloride," Wikipeddia, Free Encyclopedia, Chapman \& Hall Ltd., New York, 2009.

[16] E. Yousif, O. Hassan, A. Otaiwi and Y. Farina, "Studying the Conductivity of Poly(vinyl Chloride) Using 2-Thioacetic Acid Benzothiazole Complexes as Additives by Measuring Forbidden Energy Gap," Iraqi Journal of Polymers, Vol. 12, 2008, pp. 5-78.

[17] E. Yousif, M. Abdul Nabi and S. Aliwi, "Optical Properties Modification of Polystyrene Films by $2 \mathrm{~N}$-salicylidene-5-(p-nitro phenyl)-1,3,4-thiadiazole Complexes," Journal of Al-Nahrain University, Vol. 8, 2005, pp. 2226.

[18] M. Abdul Nabi, E. Yousif, A. Alwash and Y. Farina, "Optical Properties Modification of Poy(vinyl Chloride) Using Complexes of 2-Amino-5-(2-acetyloxyphenyl)-1,3, 4-thiadiazole," Iraqi Journal of Polymers, Vol. 13, 2009, pp. 27-63.

[19] Y. Al-Daeif, E. Yousif and M. A. Nabi, "Synthesis of New Polymers Derived from Poly(vinyl Chloride) and Study Their Optical Properties," Journal of Al-Nahrain University, Vol. 15, No. 2, 2012, pp. 79-83. 